\title{
The Changeability of Social Interaction: Formation and Evolution of Social Networks
}

\author{
Jing Shen \\ Department of Sociology, University of Toronto \\ Correspondence: Jing Shen, Department of Sociology, University of Toronto, Toronto, ON., M5S 2J4, Canada. \\ E-mail: jing.shen@mail.utoronto.ca
}

Received: April 19, 2013 Accepted: May 3, 2013 Available online: May 19, 2013

doi:10.11114/ijsss.v1i2.129 URL: http://dx.doi.org/10.11114/ijsss.v1i2.129

\begin{abstract}
As structuralists assert, structural constraints define the probabilities of social interactions. I argue, however, that structural constraints are not static. Using Carley's (1991) social interaction model as a starting point, I discuss three modified scenarios to illustrate two points: 1) shared facts can either increase or decrease the probability of a desirable interaction, and 2) at the same time, social actors' active differentiation, selection, and creation of shared facts change the interaction patterns and further reconstruct the social structure. I supplement Carley's dynamic network model by taking into account the role of social actors in the formation of social interactions; the results highlight the need to study social networks from the structural level and individual level simultaneously.
\end{abstract}

Keywords: social interaction, social structure, individual, constructive

\section{Introduction}

One of the focuses in the recent development of social network studies is network dynamics, regarding which scholars seem to have reached a consensus that social interactions between individuals are the basic component that forms all types of networks. Given this argument, understanding changes in social interactions is the key to understanding the formation and evolution of social networks. Among other work, Carley's (1991) dynamic network model convincingly shows that the number of social facts two individuals share determines the likelihood that an interaction will occur between them. Because the probability of social interaction between pairs of individuals varies, the resulting social networks involve different groups of social members and different types of tie strengths. In this regard, Carley's (1991) social interaction theory provides a helpful understanding of the formation of social networks. However, by treating social facts as exogenous determinants of social interactions, the theory fails to explain how, once formed, a social network evolves if exogenous determinants remain constant.

In this paper, I derive three adaptations of Carley's (1991) original dynamic network model to illustrate how an individual can actively alter the number of shared facts in order to increase or decrease the probability of an interaction with a specific person, which in turn leads to changes at the network level. By providing an overview of the origins and development of social network research, I demonstrate the necessity of combining structuralist and individualist perspectives in order to understand the formation process of a given network. I illustrate my theoretical approach by modifying Carley's (1991) social interaction model. Following an introduction of Carley's (1991) original theory about the formation of social networks, I present three modifications. First, instead of assuming a positive impact of a shared fact on the interaction probability between two actors, I argue that a shared fact can either increase or decrease the interaction probability. Second, I argue that as social actors with initiatives, individuals can contextualize and facilitate the occurrence of an interaction by selectively focusing on facts that increase the probability of the interaction, while downplaying those that decrease this probability. In the third modification, I show that social facts are not necessarily exogenous; individuals are able to create new facts based on their shared ones. The creation of new facts can significantly increase the cohesiveness of the whole network by fostering more dyad ties among network members. I conclude by highlighting the need for scholars to focus on the role that individual behaviors play in the dynamics of social 
networks.

\section{Overview of Social Network Research: Two Approaches}

From a structuralist perspective, social network research is based on three foundational schools (Berry, Brower, Choi, Goa, Jang, Kwon \& Word, 2004): (1) sociometric studies rooted in Gestalt psychology, which used the sociogram to diagram relationship networks among individuals; (2) the work of the Manchester anthropologists, who emphasized social structures as the structure of social roles; and (3) the research of Harvard structuralists (i.e., Harrison White and his students), who developed a block-modeling approach to measure social roles mathematically. These three schools provided the social network research that followed with a foundation of quantitative analysis methods. Through these methods, significant contributions have been made in identifying the strength of relationships, resource mobility patterns, and patterns of social interactions. However, this purely structural focus may have prevented scholars from applying social network analysis to a broad range of fields in the social sciences.

There have been some attempts to bypass the paradigm of structuralism in the study of social networks. In this regard, Granovetter's $(1973,1974)$ theory of the "strength of weak ties" initiated a new phase of social network analysis. According to Granovetter (1973), weak ties provide individuals with access to information that is useful in finding a better job, and facilitate the integration of a community at the collective level. In his paper on "network embeddedness," Granovetter (1985) further demonstrated the importance of a social network perspective, by showing that economic activities are embedded in social relations. As other scholars have summarized, in Granovetter's view, "social structures are ongoing, continually changing phenomena that are constructed historically through the specific, concrete actions of particular actors in specific circumstances." (Berry, Brower, Choi, Goa, Jang, Kwon \& Word, 2004:544) Thus, "the behavior and institutions to be analyzed are so constrained by ongoing social relations that to construe them as independent is a grievous misunderstanding."'(Granovetter, 1985:482)

Under Granovetter's influence, a school of social network analysis that focuses on the impacts of social relations on individual socioeconomic success has emerged. For example, based on the strength-of-weak-ties theory, Lin (1982, 1999a, 1999b) developed a social-resources theory, according to which social resources are unequally embedded in a pyramidal social structure. An individual who can reach a contact in a higher position has a greater probability of attaining a high-status job. To do so, mobilizing weak ties, instead of strong ties, is arguably more effective for one to reach a contact beyond one's own social status. This approach has generated a long-lasting debate on the effectiveness of tie strength, and both strong ties and weak ties have been found effective in various social settings (Bian, 1997; Bian \& Ang, 1997; Bridges \& Villemez, 1986; Marsden \& Campbell, 1984; Murray, Rankin \& Magil, 1981; PreisendÖfer \& Voss, 1988; Wegener, 1991). In addition to tie strength, studies have also shown that an individual's location within networks is important. This approach is represented by Burt's (1992) structural hole theory. According to Burt (1992), structural holes between networks not only generate non-redundant information, but also produce control benefits, because individuals whose networks span these holes have relative advantages as they negotiate favorable terms in the opportunities they pursue.

As shown in the above literature, proponents of this approach focus on the benefits that individuals accrue from resources embedded in networks, and take the existence of the network for granted, rather than regarding the network as dynamic outcome constructed by "ongoing social relations" (Granovetter, 1985:482). Research conducted within a different framework - the dynamic network approach, is thus of great importance in understanding the formation and evolutionary processes of networks.

A typical example of this type of work is analyzing social interactions as the basic component of a network (Carley, 2002; Carley, Lee \& Krackhar, 2001; Topper \& Carley, 1999). Inspired by Turner's (1988) social interaction theory, Carley (1991) characterizes social interactions as a cyclical process that starts with "action" (what occurs during an interaction), followed by "adaptation" (what happens to the individual and society as a result of interactions) and "motivation" (who interacts with whom), and eventually returns to "action." In Carley's view, the more facts two individuals share, the higher the likelihood that an interaction will occur between them. Because social structure forms in the process of social interactions, the change of a given network is ceaseless as individual interactions continue. Despite the uncertainty of social interactions, however, a relatively stable structure (social network) is possible, because the shared culture, values, and conventions among individuals can, to some degree, maintain the patterns of social interactions.

Although the social interaction model focuses on the process by which a social network is formed, this approach is mainly structuralist. A fundamental assumption of this approach is that individual behaviors are completely 
predictable, because every individual behavior can be traced back to certain environmental constraints. If this were true, under the same external conditions, identical network structures would emerge even when different individuals were embedded in the networks. However, this pattern has not been observed in real-life settings; rather, network structure varies when different individuals are involved. Namely, individuals, as active social actors, are able to alter the probabilities of interaction through their own behaviors.

Simply speaking, the previous research on social networks has fallen into two approaches: individualist and structuralist. In general, scholars from the individualist approach emphasize how social actors maneuver network resources for their own benefit and overlook changes that occur at the network level. At the same time, those working within the structuralist framework explain individual interactions as outcomes that are purely determined by the social structure and neglect individual initiatives. This raises the question of whether or not there is a possibility of bridging the two approaches, so as to study the network structure and individual behaviors simultaneously. In this paper, I thus exemplify this combined approach, in which an individual perspective is incorporated into the structuralist approach, by utilizing Carley's social interaction model. Three modifications of Carley's original model will be introduced.

\section{Carley's Social Interaction Model}

Carley's $(1991,2002)$ social interaction model examines how a network forms based on individuals' voluntary interactions. According to her, social structure is the distribution of interaction probabilities, and culture is the distribution of facts (with equal weights assumed). Consequently, the extent to which an interaction would occur between two individuals is based on the number of facts shared between them. Because different pairs of individuals share different numbers of facts, the probability of interaction also varies. Specifically, the more facts individuals share with one another, the more they are similar to one another, and thus the more likely it is that they will interact with one another (see Diagram 1; quoted from Carley, 1991: 337). This pattern explains the homophily principle of social networks. The model also shows that individuals are much more likely to interact with those with whom they share many facts than with those with whom they share few facts. Thus, the model also explains variations in tie strength, as shown in the following Diagram 1.

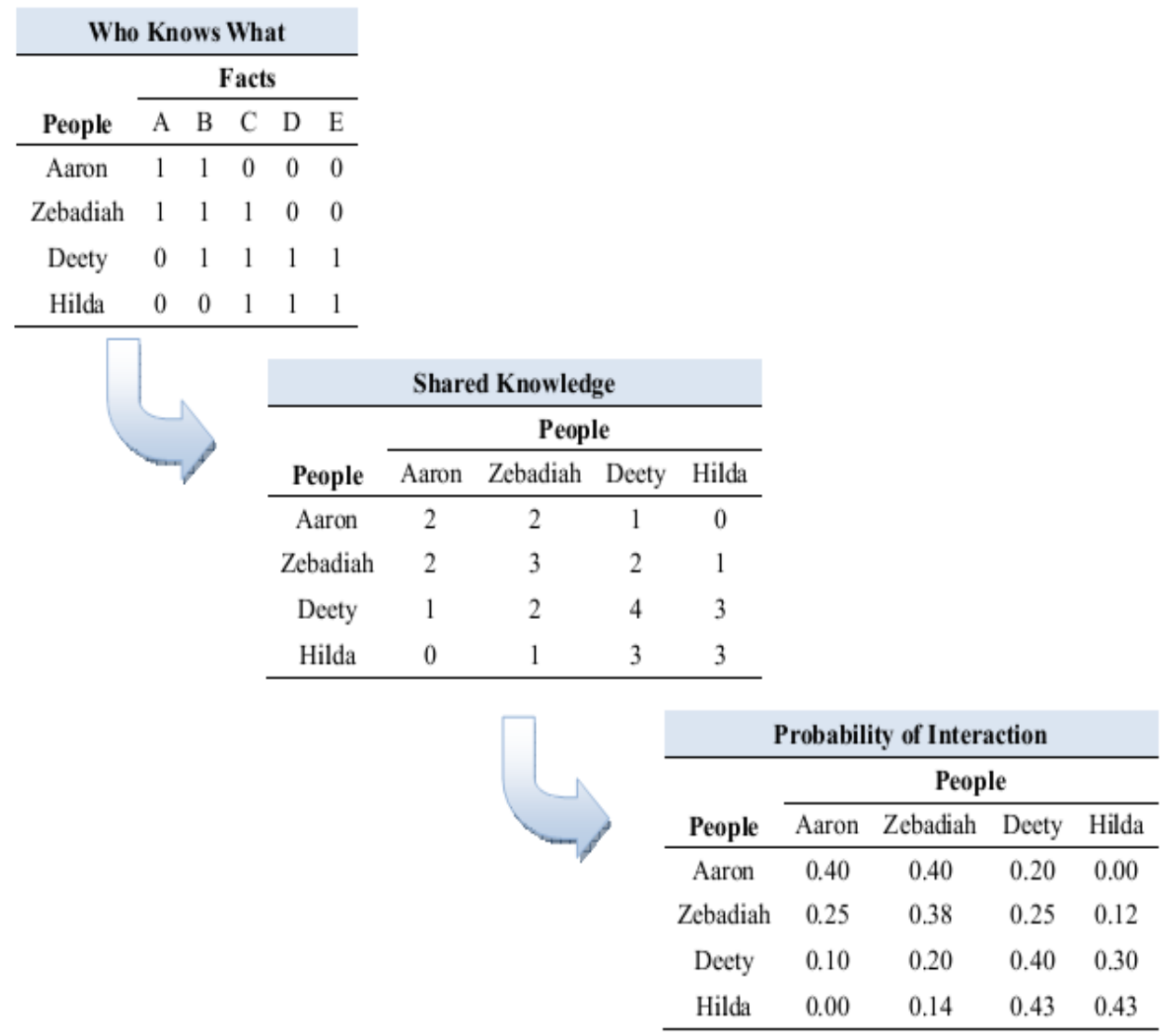

Diagram 1. A small society

(Original diagram is seen in “A Theory of Group Stability.” Carley, 1991: 337) 
While Carley's social interaction model explains the formation of social networks to a certain degree, it does not account for either variations in the formation process of networks or their evolution. Particularly, why would the same environmental constraints (i.e., the same number of facts) cause different network structures among different individuals? And why would a social network still change when there is no external influence on the number of shared facts? Individual initiatives must be taken into account to answer the above questions. Arguably, the relationship between social structure and individual social actors is reciprocal. While social structure constrains individual behaviors, individuals can also shape the social structure by their behavior. As Lin noted, "social capital contains three elements intersecting structure and action: the structural (embeddedness), opportunity (accessibility) and action-oriented (use) aspects" (Lin, 1999:35). The three elements refer to, respectively, resources embedded in the network, channels or means by which an individual accesses desirable resources, and subsequent outcomes resulting from individuals' actions at the structural level. This relationship can be represented in a circular diagram, as shown in Diagram 2.

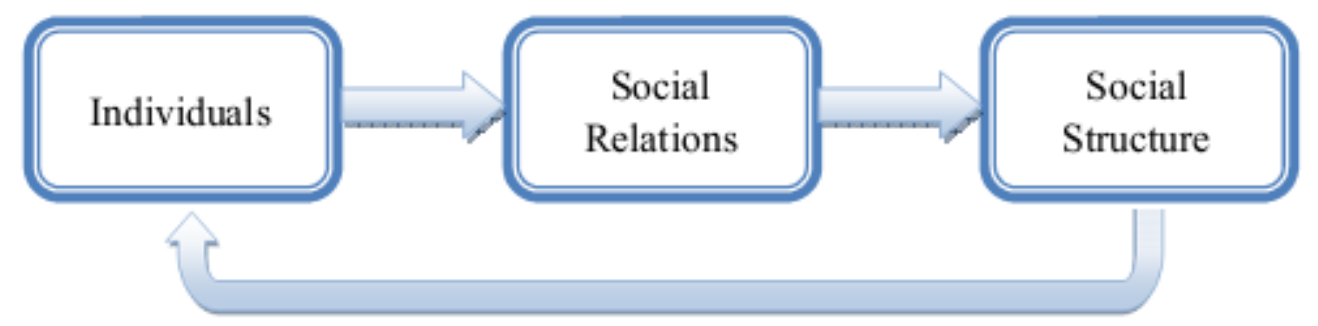

Diagram 2. Reciprocity between individuals and social structure

(Based on Lin's definition of social capital. Lin, 1999b: 35)

Individuals are able to change social structure through shaping the social relations among them, while their behaviors are indeed constrained by social structure. In the following sections, I modify Carley's social interaction model by elaborating on the ways in which individuals can use their behaviors to modify the probability of a social interaction for their own purposes.

\section{Three Modified Versions}

\subsection{Modification 1: Negative Impacts of Shared Social Facts}

In contrast to Carley's assumption that shared social facts always increase the chance of social interaction, I argue that shared facts can either increase or decrease the probability of social interaction. Consider a typical example: two hypothetical individuals become friends when they work together and have a similar status at the workplace. Their shared facts about friendship lead to interactions beyond the workplace, such as spending time together after work, inviting one another to social gatherings, visiting one another's houses, and so on. The frequency of their interactions is high because interactions occur in both the workplace and private settings. However, if one of the friends is promoted, the introduction of newly shared facts about a supervisor-subordinate relationship may not facilitate more interactions between the two, because the nature of such a relationship emphasizes social distance in order to maintain the authority of the supervisor, and thus prevents informal, emotion-driven interactions. Because they share a common understanding of the social relation between a supervisor and a subordinate, these two individuals may now choose to meet only in formal settings and to discuss business, instead of personal issues. It is thus obvious that the newly emerged shared facts decrease, rather than increase, the probability of their interactions.

As shown in Diagram 3, the same four individuals in Carley's (1991) original model still share five facts. My modification is to assign directions to these facts: While facts A, C, and D still impact the likelihood of an interaction positively, facts $\mathrm{B}$ and $\mathrm{E}$ now exert negative impacts on the occurrence of a voluntary interaction. Consequently, the probability of an interaction between each pair of different individuals is determined by the result of a subtraction of the negative shared facts from the positive shared facts. If the number of shared fact is negative between two individuals, these two individuals would avoid interacting with one another. Thus, the probability of an interaction determined by a negative number of shared facts is zero. It is also obvious that the direction of a social fact should apply only when one interacts with a second individual. When one interacts with him- or herself, the probability of an interaction is determined by the summation of the absolute values of facts one possesses. 


\begin{tabular}{cccccc}
\multicolumn{6}{c}{ Who Knows What } \\
\hline & \multicolumn{5}{c}{ Facts } \\
\cline { 2 - 6 } People & A & - B & C & D & - E \\
\hline Aaron & 1 & 1 & 0 & 0 & 0 \\
Zebadiah & 1 & 1 & 1 & 0 & 0 \\
Deety & 0 & 1 & 1 & 1 & 1 \\
Hilda & 0 & 0 & 1 & 1 & 1 \\
\hline
\end{tabular}

\begin{tabular}{|clllll}
\hline & \multicolumn{5}{c}{ Shared Knowledge } \\
\cline { 2 - 6 } & & \multicolumn{4}{c}{ People } \\
\cline { 2 - 6 } & People & Aaron & Zebadiah & Deety & Hilda \\
\hline Aaron & 2 & $1-1=0$ & -1 & 0 \\
Zebadiah & $1-1=0$ & 3 & $1-1=0$ & 1 \\
Deety & -1 & $1-1=0$ & 4 & $2-1=1$ \\
Hilda & 0 & 1 & $2-1=1$ & 3 \\
\hline
\end{tabular}

\begin{tabular}{|c|c|c|c|c|}
\hline \multicolumn{5}{|c|}{ Probability of Interaction } \\
\hline \multirow[b]{2}{*}{ People } & \multicolumn{4}{|c|}{ People } \\
\hline & Aaron & Zebadiah & Deety & Hilda \\
\hline Aaron & 1.00 & 0.00 & 0.00 & 0.00 \\
\hline Zebadiah & 0.00 & 0.75 & 0.00 & 0.25 \\
\hline Deety & 0.00 & 0.00 & 0.80 & 0.20 \\
\hline Hilda & 0.00 & 0.20 & 0.20 & 0.60 \\
\hline
\end{tabular}

Diagram 3. Negative impacts of shared social facts

As shown in the "Probability of Interaction" table in Diagram 3, the existence of a shared negative fact sharply increases the probability of an individual interacting with him- or herself, and decreases the number of alters with whom the individual may be able to interact. Compared to the scenario shown in Diagram 1, in the Diagram 3 each network member has a smaller likelihood of a possible interaction with an alter. Namely, a shared fact among network members prevents the occurrence of a social interaction. Arguably, the more negative social facts the network members share, the less likely it is that they will interact with one another. As network members become increasingly isolated from one another, the initially existing network will gradually disappear. This pattern can explain the failure of some organizations. While the number of shared facts increases as the organization evolves, not all shared facts facilitate interactions among members. The probabilities of social interaction would exponentially decrease as group members' isolated positions create more negative shared facts. As Diagram 3 shows, sharing negative facts may cause a member to become completely detached from the group. A group would subsequently collapse when most of its members reach a minimum likelihood of interacting with other members.

\subsection{Modification 2: Contextualization and Selective Use of Shared Social Facts}

Although the outcome described in the previous section may occur, another possibility is that the two hypothetical individuals may maintain their friendship, while also accepting their new superior-subordinate relationship. To do so, the two may interact with one another based on a superior-subordinate relationship in the workplace, but interact as friends after work. Although social facts that influence the probability of social interactions in opposite directions co-exist, social actors have the ability to decide which social facts dominate in a certain context. In other words, social actors are able to contextualize shared facts, by emphasizing those that encourage a desirable interaction and downplaying those that prevent the occurrence of this interaction. As shown in the above example, to maintain their friendship, the two individuals must ignore the supervisor-subordinate relationship and interact like friends when they are in a private setting. I thus modify Carley's model as shown in Diagram 4. 


\begin{tabular}{cc|ccc|c}
\hline \multicolumn{5}{c}{ Who Knows What } \\
\hline & \multicolumn{5}{c}{ Facts } \\
\cline { 2 - 7 } People & A & -B & C & D & -E \\
\hline Aaron & 1 & 1 & 0 & 0 & 0 \\
Zebadiah & 1 & 1 & 1 & 0 & 9 \\
Deety & 0 & 1 & 1 & 1 & 1 \\
Hilda & 0 & 0 & 1 & 1 & 1 \\
\hline
\end{tabular}

\begin{tabular}{cccccc}
\hline & \multicolumn{5}{c}{ Shared Knowledge } \\
\cline { 2 - 6 } & & \multicolumn{4}{c}{ People } \\
\cline { 2 - 6 } & People & Aaron & Zebadiah & Deety & Hilda \\
\hline Aaron & $2^{1}$ & 1 & 0 & 0 \\
Zebadiah & 1 & 3 & 1 & 1 \\
Deety & 0 & 1 & 4 & 2 \\
Hilda & 0 & 1 & 2 & 3 \\
\hline
\end{tabular}

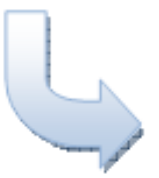

\begin{tabular}{ccccc}
\multicolumn{5}{c}{ Probability of Interaction } \\
\hline \multirow{4}{*}{ People } & \multicolumn{4}{c}{ People } \\
\cline { 2 - 5 } & Aaron & Zebadiah & Deety & Hilda \\
\hline Aaron & $2 / 3$ & $1 / 3$ & 0.00 & 0.00 \\
Zebadiah & $1 / 6$ & $1 / 2$ & $1 / 6$ & $1 / 6$ \\
Deety & 0.00 & $1 / 7$ & $4 / 7$ & $2 / 7$ \\
Hilda & 0.00 & $1 / 6$ & $1 / 3$ & $1 / 2$ \\
\hline
\end{tabular}

Diagram 4. Contextualization and selective use of shared social facts

In Diagram 4, I emphasize that the direction of a shared fact's impact on the probability of a social interaction is contextualized. Assume that the impacts of shared facts B and E are negative on a specific interaction. For individuals who desire the occurrence of this interaction, they can actively choose to block facts $\mathrm{B}$ and $\mathrm{E}$ and only focus on facts $\mathrm{A}, \mathrm{C}$, and $\mathrm{D}$, which encourage this interaction. Thus, the probability of this specific interaction is now determined not by the difference of the subtraction of negative facts from positive facts, but only by the number of positive facts. Compared to the scenario in Diagram3, Diagram 4 shows that the first three actors have all increased their chances of interacting with other members by ignoring negative facts. Although the last actor has the opportunity to interact with only one alter, the probability of an interaction between these two increases significantly.

\subsection{Modification 3: Creation of New Shared Facts}

In addition to blocking negative shared facts in order to reduce social distance and increase the probability of an interaction, social actors can also create new facts that increase the probability of a desirable interaction. The actions of members of a cohesive immigrant community provide a helpful example in this case. Before immigration, the community members may have had no chance of interacting with one another. Once immigration united them, their interactions would focus mainly on shared facts about immigrant identification, especially if the individuals had different ethnic and linguistic backgrounds. However, sharing an immigrant identity does not guarantee social interactions between immigrants, since not all immigrant communities are cohesive. What distinguishes a cohesive immigrant community from a socially disorganized one is that members of a cohesive community do not just regard other members as "other immigrants." Members often regard one another as brothers and sisters, and consider the community a family. The presence of new shared facts that were created based on a kind of pseudo-kinship leads to much stronger interactions than mere immigrant identification does.

On the other hand, research on inter-firm networks provides a second example. Scholars have found that 
suppliers and manufacturers build close relations that are based on the market relation, but also extend far beyond the market relationship per se. Such embedded network relationships are characterized by trust and personal ties, which are difficult to replicate via markets, contracts, or vertical integration (Granovetter, 1985; Simon and Warner, 1992; Uzzi, 1996). It is these kinds of close relationships, rather than pure market relationships, which maintain long-term interactions between actors. For example, Boisot and Child (1996) argued that China's rapid economic development is characterized as network capitalism because the codification of information, communal property rights, and the organization of economic transactions are all limited. The authors argue that because of traditional Chinese culture that is embedded in economic activities, the relationships between those who fill all types of roles in the market are much closer than those in Western markets, and that this is especially true when it comes to the distinctive relationships between the governmental authorities and the enterprises over which they have power. In Western modernization theory, there is a clear division of roles between the government as the political administrator and enterprises as economic actors. In the Chinese context, however, the relationship between the government and enterprises is based on interpersonal reciprocal obligations (guanxi), whose intimacy extends far beyond the conceptual relations between the government and enterprises. Although the Chinese cultural tradition is not a new creation, its application to economic activities in the market is new. My final modification of Carley's model is thus shown in Diagram 5.

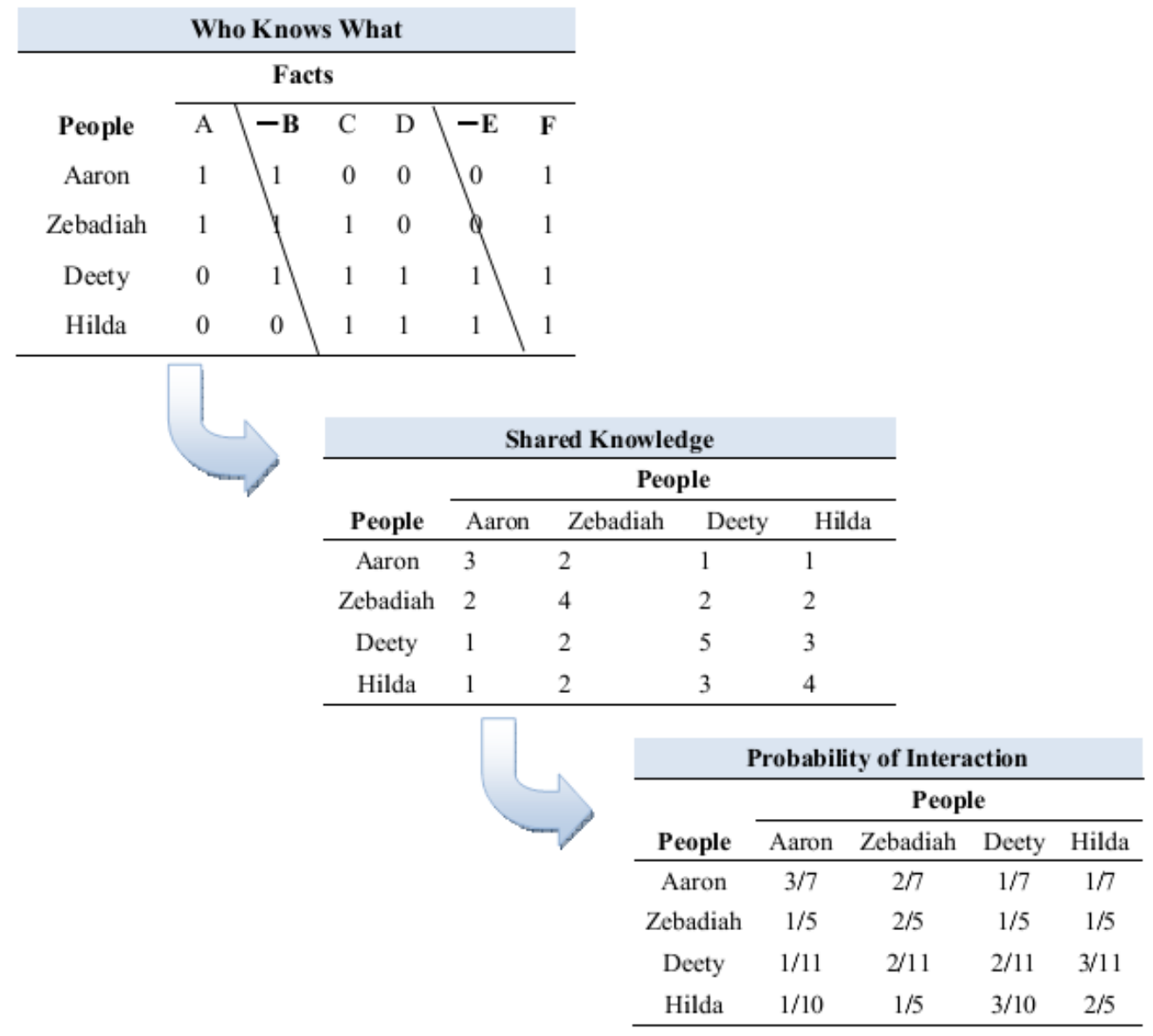

Diagram 5. Creation of new shared facts

Compared with Diagram 4, Diagram 5 demonstrates that the newly created shared fact increases the possibility of an individual interacting with other group members, while decreasing the probability of interacting with himor herself. As a result, more dyad ties are created, which means the average number of alters each network member possesses has increased. As each network member interacts more frequently with other members, the overall cohesiveness of a network increases as well. Thus, the creation of a positive shared fact can increase social capital not only for individual network members, but also for the network as a whole. This pattern has been strongly demonstrated by social capital studies at the community level (Bourdieu [1983]1986; Coleman 1988; Portes 1998). 


\section{Conclusion}

In her dynamic network model, Carley (1991) decomposed a society's cultural and structural elements into facts that are shared by social members. Sharing facts lead to interactions between members of social networks. The more facts two members share, the more likely they are to interact with one another. Because the number of shared facts between each pair of social actors varies, a diverse set of social relationships develops. While I agree on the fundamental role that shared facts play in network formation, I argue that individual initiatives should not be neglected in descriptions of this process. This paper demonstrates that not all shared facts play constructive roles in fostering social interactions. However, as active social actors, individuals can decide which shared facts they refer to in a particular social context. Pairs of individuals define the properties of shared facts, and distinguish the facts that increase interaction opportunities from those that constrain interactions. By prioritizing positive shared facts and blocking negative ones, individuals can actualize interactions with their target subjects. A more important strategy for increasing the chance of interactions is creating new shared facts that facilitate social interactions. The creation of a positive shared fact, such as pseudo-kinship in immigrant communities or economic activities, decreases the chance of an individual interacting with himself or herself, in other words, the probability of isolation. Correspondingly, more dyad ties are created as a result of the new positive fact. Individual network members thus gain more social capital as the diversity of their personal networks increases. Consequently, social capital at the network level also increases as cohesiveness increases within the network.

Indeed, as structuralists have noted, structural constraints (the existence of shared facts) define the probabilities of social interactions. However, structural constraints are not static. Social actors' active differentiation, selection, and creation of shared facts can change interaction patterns and further reconstruct the social structure. Future studies should explore the motives of individual actors as they strategize in increasing or decreasing social interactions with others. Rational choice theory may be one possible framework for such research; as rational actors, individuals seek to maximize the benefits gained from social interactions, while minimizing the tangible and intangible costs. This may provide an answer to the question "What type of relationships do individuals want to construct, and with whom?" in future studies.

In summary, this paper supplements Carley's dynamic network model by accounting for the role of social actors in the development of social interactions. My modifications based on Carley's model explain the ways in which social structure can be reconstructed and reshaped in the process of social interactions. My modifications also call for scholars to focus on social structure and individuals simultaneously in future network analysis. This is because "individuals are the individuals located in the social structure, and the social structure is the structure composed of the actions of individuals." (Thireau \& Mak, 2000:34)

\section{References}

Berry, F. S., Brower, R S., \& Choi, S. O. (2004). Three Traditions of Network Research: What the Public Management Research Agenda Can Learn from Other Research Communities. Public Administration Review, 64(5), 539-52. http://dx.doi.org/10.1111/j.1540-6210.2004.00402.x

Bian, Y. J. (1997). Bringing Strong Ties Back in: Indirect Connection, Bridges, and Job Search in China. American Sociological Review, 62(3), 366-85. http://dx.doi.org/10.2307/2657311

Bian, Y. J., \& Ang, S. (1997). Guanxi Networks and Job Mobility in China and Singapore. Social Forces, 75, 981-1006.

Boisot, M., Child, J. (1996). From Fiefs to Clans and Network Capitalism, Explaining China's Emerging Economic Order. Administrative Science Quarterly, 41(4), 600-28. http://dx.doi.org/10.2307/2393869

Bourdieu, Pierre. ([1983]1986). The Forms of Capital. In J. G. Richardson (Ed.) Handbook of Theory and Research for the Sociology of Education (pp.241-58). Westport, CT: Greenwood Press.

Bridge, W. P., \& Villemez, W. J. (1986). Informal Hiring and Income in the Labor Market. American Sociological Review, 51, 574-82. http://dx.doi.org/10.2307/2095589

Burt, R. S. (1992). Structural Holes: The Social Structure of Competition. Cambridge, MA: Harvard University Press.

Carley, K. M. (1991). A Theory of Group Stability. American Sociology Review, 56(3), 331-54. http://dx.doi.org/10.2307/2096108

Carley, K. M. (2002). Inhibiting Adaptation. In Proceedings of the 2002 Command and Control Research and Technology Symposium (pp.1-10). Monterey, CA: Naval Postgraduate School.

Carley, K. M., Lee, J., \& Krackhardt, D. (2001). Destabilizing Networks. Connections, 24(3), 31-44. 
Coleman, J. (1988). Social Capital in the Creation of Human Capital. The American Journal of Sociology 94 (Supplement: Organizations and Institutions: Sociological and Economic Approaches to the Analysis of Social Structure), S95-S120.

Granovetter, Mark. (1973). The Strength of Weak Ties. American Journal of Sociology, 78(May), 1360-1380. http://dx.doi.org/10.1086/225469

Granovetter, Mark. (1974). Getting a Job: A Study of Contacts and Careers. Cambridge, MA: Harvard University Press.

Granovetter, Mark. (1985). Economic Action and Social Structure: The Problem of Embeddedness. American Journal of Sociology, 91, 481-510. http://dx.doi.org/10.1086/228311

Lin, Nan. (1982). Social Resources and Instrumental Action. In P. Marsden and N. Lin (Eds.) Social Structure and Network Analysis (pp.131-47). Beverly Hills, CA: Sage.

Lin, Nan. (1999a). Building a Network Theory of Social Capital. Connections, 22(1), $28-51$.

Lin, Nan. (1999b). Social Networks and Status Attainment. Annual Review of Sociology, 25, 467-87. http://dx.doi.org/10.1146/annurev.soc.25.1.467

Marsden, P. V. \& Campbell, K. E. (1984). Measuring Tie Strength. Social Forces 63, 482-501.

Murray, S. O., Rankin, J. H., \& Magill, D. W. (1981). Strong Ties and Job Information. Sociology of Work and Occupations, 8, 119-36. http://dx.doi.org/10.1177/073088848100800107

Portes, A. (1998). Social Capital: Its Origins and Applications in Modern Sociology. Annual Review of Sociology, 24, 1-24. http://dx.doi.org/10.1146/annurev.soc.24.1.1

PreisendÖfer, P., \& Voss, T. (1988). Arbeitsmarket und Soziale Netzwerke. [Labor Market and Social Networks]. Soziale Welt, 39,104-19.

Thireau, Isabelle, and Kong Mak. (2000). Disputes and Agreements: An Approach to Studying Changes in Social Rules. Tsinghua Sociological Review (Special Issue), Lujiang Express.

Topper, C. M., \& Carley, K. M. (1999). A Structural Perspective on the Emergence of Network Organizations. Journal of Mathematical Sociology, 24(1), 1-29. http://dx.doi.org/10.1080/0022250X.1999.9990229

Turner, J. H. (1988). A Theory of Social Interaction. Stanford University Press: Stanford, California.

Simon, C. J., \& Warner, J. T. (1992). Matchmaker, Matchmaker: The Effect of Old Boy Networks on Job Match Quality, Earnings, and Tenure. Journal of Labor Economics, 10, 306-29. http://dx.doi.org/10.1086/298289

Uzzi, B. (1996). The Sources and Consequences of Embeddedness for the Economic Performance of Organizations: The Network Effect. American Journal of Sociology, 61, 674-698. http://dx.doi.org/10.2307/2096399

Wegener, B. (1991). Job Mobility and Social Ties: Social Resources, Prior Job, and Status Attainment. American Sociological Review, 56, 60-71. http://dx.doi.org/10.2307/2095673

\section{Notes}

Note 1. Fact blocking only occurs when one interacts with another person. For an individual's probability of interacting with one's self, it should be determined by the total number of facts one possesses.

\section{(cc) $\mathrm{BY}$}

This work is licensed under a Creative Commons Attribution 3.0 License. 